\title{
Teaching Policy Design: Themes, Topics \& Techniques
}

\author{
Azad Singh Balia, Caner Bakir ${ }^{b}$, Michael Howlettc, Jenny M. Lewis ${ }^{d}$, Scott Schmidte ${ }^{*}$ \\ ${ }^{a}$ Australian National University \\ 'Koç University \\ 'Simon Fraser University \\ 'The University of Melbourne \\ e*Georgetown University, ss4210@georgetown.edu
}

\begin{abstract}
:
After briefly discussing the origins of the policy design field, this paper examines aspects of design paedagogy in policy schools and programmes. It sets out a series of topics which University level courses typically cover, explains their importance to the field, and what is typically addressed in coursework. These include subjects such as: what is policy design and how it has evolved; introducing policy tools and portfolios; issues around persuasive design, targeting and compliance; who are the policy designers and how do they think and operate; what is meant by policy effectiveness; what are design best practices; how designs and designers deal with uncertainty, conflict and controversy; and what are the future directions in which the field is heading, why and what this means for both design paedagogy and practice. The chapter then turns to paedagogical techniques deployed in these courses across four continents, dealing with differences between undergraduate and graduate level instruction, case-based instruction and on-line and distance learning, as well as efforts to integrate co-design and innovative pedagogies including new methods and techniques such as Big Data methodologies and policy labs and experiments.
\end{abstract}

Keywords: policy, design, education, paedagogy

\section{Introduction: Is Policy Design Teachable?}

Policy design denotes a conscious effort to marshal governing resources and direct them towards the attainment of government goals (Howlett 2019a). A design typically involves the creation of a mix or bundle of policy tools which can reasonably be expected to work together to attain a government goal or goals (Salamon 2002; Hood 1986). These goals are varied and range from resolving well known and well-understood social problems such as healthcare in the public interest to the personal self-aggrandizement of leaders and the promotion of highly selective private or group partisan self-interests (Howlett 2020). What separates "design" 
from "non-design" efforts in this area, however, is not so much the purpose of the policy but rather the manner in which a policy response or output utilizes knowledge and evidence about "what works" rather than being enacted purely through inter-group bargaining or solely upon the basis of leadership experience or intuition (Howlett and Mukherjee 2017; Newman and Nurfaiza 2020; Johnson and Cook 2014).

This emphasis on knowledge accumulation and mobilization in the creation of bundles of policy tools is what allows policy design to be taught in an academic setting (Vesely 2020). That is, if policy design was purely experiential in nature, then it would be more craft than art and better served through apprenticeship programmes and mentoring than university-based policy courses which attempt to impart codified information on "what works" to students (Weimer 1992; He et al 2016). While professional and case-oriented instruction in these venues do emphasize 'real world' or experiential knowledge, the policy schools which have expanded rapidly around the globe have settled on a core curriculum which includes many aspects of policy design. This includes courses dealing with topics such as institutional design, policy processes and policy instrument analysis as well as courses dealing with political feasibility, policy analysis and evaluation and other such design-oriented aspects of policymaking (Pal and Clark 2016a and 2016b).

Many gaps, of course, continue to exist in this curriculum, including older topics such as formal policy analysis through techniques such as cost-benefit or cost-effectiveness analysis which are often lacking in new more process-oriented programmes (Wu et al 2012). And these gaps also extend to newer aspects of policy study and activity such as digital governance (Clarke and Craft 2017) and Big Data (Leitner and Steifmueller 2019; El-Talaiwi 2021) which are often poorly represented in current policy school offerings which take time to develop. And these problems also extend to the subject of policy design itself, which at present is only taught as a core, stand-alone subject in few schools and programmes (see sections on paedagogy in Annual Review of Policy Design Vol 72019 and Vol 52017 for examples of course syllabi in this field).

Although a growth area in the field, policy design courses have not yet become commonplace in policy school curricula, although the signs of this beginning to happen are quite clear and will no doubt increase in the near future.

Policy Design courses exist in other places besides academe, of course. Some design schools themselves have also begun to develop curriculum and courses that attempt to use design thinking as a means for addressing policy formulation (Dorst 2011; Bason and Schnieder 2014), and such courses are a staple of executive level professional management training programmes, even if they are not always labelled as such (Rasmussen 2016; Manwairing et al 2019; Johansson-Sköldberg et al 2013). These courses may offer a less traditional route to understanding policy development and design, but also often introduce non-traditional techniques and more 'designerly' ways of knowing into the interface of policy and design (Cross 1982).

But what do these policy design courses entail? How are they structured and what subject matter is typically covered? And what paedagogical techniques are considered suitable for such courses? Even if these topics are scattered over a number of courses rather than a single dedicated one, and/or delivered in a variety of mediums and through a range of techniques, 
what sorts of topics need to be covered by them and what are the strengths and weaknesses of different available paedagogies? And how are these varying ideas on the convergence of policy and design reconciled with one another? These are all subjects covered in this chapter.

After briefly discussing the origins of the policy design field, the chapter examines aspects of paedagogy around the subject in policy schools and programmes. It sets out a series of topics which courses typically cover, explains their importance to the field, and how they are typically addressed in coursework.

The chapter then turns to paedagogical techniques deployed in existing courses located in four continents, dealing with differences between undergraduate and graduate level instruction, case-based instruction and on-line and distance learning, as well as efforts to integrate co-design and innovative pedagogies including new methods and techniques from Big Data methodologies to the promotion and creation of policy labs and experiments.

\section{Key Topics Covered in Policy Design Courses}

Examination of existing University course syllabi (Annual Review of Policy Design 2017 and 2019) and commonly used textbooks (Howlett 2011 and 2019) reveal a standard set of readings and topics in policy design instruction in academic settings organized around the "5Ws": the "Who, What, Where, When and Why" of policy design. Courses which deal with the subject in this way can be found in the United States, Turkey, Canada, Australia and elsewhere (Annual Review of Policy Design 2017 and 2019).

These courses are typically intended to define key concepts, survey past and present research in the field, and establish the history of thinking about policy design within the more general discipline of the policy sciences (Bobrow 2006). In particular, these courses tend to highlight the difficulties of policy design, including notably an emphasis on the vagaries of policy formulation (deLeon 1992) and the problematics of policy implementation (May 2003) which may lead even the best-formulated plans to go astray.

These courses go beyond simply describing problems to provide guidance on what it means for a policy to be "effective" (Peters et al 2018) and how erstwhile policy designers can overcome problems related to knowledge generation and utilization, such as uncertainty and the clash of interests which typically characterizes policy deliberations (Manski 2011 and 2013). They also spend a great deal of time discussing the policy process and who makes policy as well as the nature of "policy work" and policy advice (Colebatch 2006; Verbuggen 2011). This is in addition to providing basic data and instruction on the nature of common policy tools and instruments as well as the patterns and reasons found for their selection and use in different sectors, governments and time periods (Howlett 2019b).

In many cases, these subjects are taught in single semester-long course which includes between 1-3 weeks on topics such as: what is policy design; introducing policy tools and portfolios; persuasive design, targeting and compliance; who are the policy designers and how do they think and operate; what is meant by policy effectiveness; what are design best practices; how do designs and designers deal with uncertainty, conflict and controversy; and what are the future directions in which the field is heading. However, in other cases these 
subjects are spread across a number of courses and included in other courses dealing with subjects such as policy evaluation, policy analysis, introduction to public policy and others which serve to provide the background and contextual knowledge needed for more advanced consideration of policy designs and designing. Each of these topics is addressed in turn below and some key sub-topics, authors and readings listed.

First there is the issue of "Why Policy Design". This is usually introduced as a way of separating the field of policy design from that of policy studies while noting the close links between the two. Important topics covered include the derivation of key definitions of design both in the policy field and elsewhere, usually drawing on classic works such as Dorst (1995 and 2011), Rein and Schon (1994 and Schon and Rein 1996; Schon 1984; 1986; 1990; Waks 2001) and in the policy sphere, Dryzek (Bobrow and Dryzek 1987; Dryzek and Ripley 1988), Bobrow (2006) and Linder and Peters (1984; 1987; 1988; 1990a; 1990b; 1990c; 1991; 1992). The need to arrive at some criteria for the evaluation of 'good' designs such as efficiency and effectiveness are stressed (Peters 2018), along with a clear-eyed examination of problems around uncertainty in terms of policy outcomes and target behaviour addressed, using citing Morgan and Henrion (1990) and Walker and his colleagues (Walker et al 2013a and 2013b; Walker and Marchau 2004).

After having established that there is such a thing as policy design, attention is then paid to distinguishing between different kinds and types of design or "What is Policy Design". This introduces the basic distinction between design and non-design mentioned above (Howlett and Mukherjee 2017). However, it also broaches the differences between different design modalities linked to the degree to which a complete package of policies is constructed at a single point in time or gradually developed through incremental processes such as "patching", "layering", or "stretching" (Thelen 2004; van der Heijden 2011; Feindt and Flynn 2009; Howlett and Rayner 2013; Howlett et al 2018).

In this work, the nuances of these evolutionary processes and the possibility of the intentional or unintentional sequencing or alteration of policy components over time is a key subject and its relationship to policy robustness and resilience a central focus of discussion (Howlett 2019).

And an expansion of interest on policy instruments is also apparent and crucially concerned with questions of policy design (Howlett 2019a). The study of policy instruments and their effects can either be highly practical and vocationally oriented, focused on understanding which instruments might achieve the most effective outcomes in a specific situation. It might also be much more design thinking focussed, such as the States of Change program, originally established by Nesta UK, and now being rolled out as training for public servants in a number of national jurisdictions (States of Change 2020).

The teaching of policy design can also be theory driven and research heavy, although that is less likely to be the focus in professional training and 'on the job' vocational courses.

A third topic then broached is "Where is Policy Design". This entails a discussion of where policy design occurs within a government system. This topic typically embraces issues such as the notion of design spaces and also the varied organizational forms from political decisionmaking bodies such as cabinets and legislature to specialized policy or design units and design labs where design deliberations take place (Howlett and Mukherjee 2018; Mortati 2019). 
A fourth topic is "When is Policy Design". This involves a discussion of the details and particularities of the policy process and especially policy formulation - when design proposals emerge - and implementation - when they are adopted and have to be put into place (Howlett and Mukherjee 2017; Lindquist 2006; May 2003). An important sub-topic here concerns the social designation or construction of policy targets, a subject covered in many classic works by Schneider and Ingram, for example (1990a; 1990b; 1993; 1994; 1997; 2005).

This contributes to the fifth topic which is especially common in political science-oriented courses: "Who is Policy Design". This includes studies of both policy advice and policy work (Veselý 2016). It often engages in an extended discussion of specialized actors such as interest groups, think tanks, research institutes and lobbyists who can have an outsized impact on designs and designing (Fraussen and Halpin 2016; Nelson and Yackee 2012). It is also common to link these to specialized terms developed within academe to group and classify these actors such as design coalitions (Haelg et al 2020); instrument constituencies (Simons and Voss 2017) and policy advisory systems (Hustedt 2013; Craft and Halligan 2016) as well as the sociologically inspired techniques - such as social network analysis - which can be used to identify these actors, their ideas and the interactions between them (McNutt and Pal 2011).

A final topic often used to conclude such a course is future-oriented, looking at "Where is Policy Design going". This introduces such topics as new analytical techniques, new actors and processes such as policy experiments and policy labs, and the role of data science, design thinking, and co-design which are altering the ways policy design is conceived and practiced (Wellstead 2020; Olejniczak 2020; Lewis et al 2020; Lee and Ma 2019; Giest and Mukherjee 2020).

\section{Differences Between Undergraduate, Graduate and Professional Training}

The commonly received wisdom around teaching public policy and public administration at different levels (undergraduate, graduate), directed at different audiences (future/current civil servants, government policy makers, consultants, not-for-profit leaders, policy researchers), and underpinned by specific emphases (research-focused and theory heavy, versus vocational and professional training) is by no means a universally held and applied set of strictures.

Some higher education institutions and academics firmly hold the belief that public policy should not and perhaps even cannot be taught to undergraduates, for example, but requires an undergraduate education to provide the context in which government problem-solving and other kinds of policy activity may be understood and managed. But other institutions prefer to have policy introduced early in the undergraduate curriculum, alongside political science, in order to cover both the inputs and outputs of the political system in equal detail and emphasis. And others still, regard politics and/or economics and policy as inextricably linked and would not contemplate separating out policy from politics in curriculum design and subject offerings, regardless of which level the subject is taught. Still other disciplines from Geography to Criminology and Social Work, among many others, view policymaking as a 
supplementary subject to their disciplinary specialization and therefore consider it an appropriate subject for specialized upper division or senior undergraduate courses but not lower-level or introductory ones which focus instead on core disciplinary terminology and insights.

Further, in some countries in Asia and Europe, some institutions are charged with the delivery of policy courses that are a requirement before entering the national (and sub-national) civil service. In other nations, it is more common to begin working in public service organizations with an undergraduate degree - often not including having studied any politics and/or policy, and then to take up part time study while in these posts, out of general curiosity, or specifically to gain knowledge or frameworks that help undertake these posts, or in order to progress to a more senior post in the future. In this latter situation, the individual might be either partially or fully sponsored by their employing organization (with time in lieu or fee subsidies or both in recognition that this education will support the development of knowledge acquisition and new skills for their staff) thereby also growing the talent within the organization) in enrolment in graduate degree or certificate programmes at Universities or Civil Service Institutes.

\section{Integrating Policy Studies and Studies of Policy Design}

Given these differently structured types and levels of public policy education the tertiary level, where does policy design fit? Should different aspects of the subject be taught, depending on the specifics of the overall degree/diploma/certificate, as currently occurs with public policy courses? To answer this question, requires delving into the meaning of policy design and how it might be variously constructed for different groups of students.

In most generalist public policy subjects, and in the teaching of policy as part of political science, students are often introduced to some variant of the policy cycle - a sequential model or heuristic of the stages in the 'ideal type' policy process: moving from agenda setting to policy formulation to decision making to policy implementation and finally, monitoring and evaluation (see for example, Howlett and Ramesh 2003). Extended versions of this sometimes include 'policy design' as a stage. For example, a version by Young and Quinn (2002) places policy design between the stages of decision making (choice of solution) and policy implementation. Other versions, such as the Bridgman and Davis (2004) version instead use the term 'policy instruments', and place this earlier in the cycle, following on from identifying issues and policy analysis, but before consultation, coordination and decision making.

Integrating policy design with various versions of the policy cycle is appealing for the teaching of public policy at a broad level, but when the emphasis is on instruction in the specifics of policy design, the subject needs to be rendered as more than just one stage in a larger policy process. Herbert Simon (1969) in The Sciences of the Artificial, for example, made design central and also much more encompassing than is suggested by simply adding design as a stage of policymaking. In stating that: "Everyone designs who devises courses of action aimed at changing existing situations into preferred ones", Simon effectively likened design to the entirety of the policymaking process - which involves developing courses of action aimed at changing situations. In recent times, Simon's work has attracted renewed attention, not just 
because of the embrace and widespread adoption of behavioural insights (such as "design experiments") to policymaking in practice, but also because of the broader insights that his work on design generates in theory.

In fact, design researchers have increasingly moved into the policy sphere as they have become interested in using design knowledge and techniques to help solve complex societal problems, such as in the current trend to apply the insights of 'design thinking' from product and service design to policymaking. The work of design researchers such as Kees Dorst (2015) highlights how the re-framing of problems through design thinking can be used to better understand them. Others working in design leadership roles as heads of design labs and similar design-led organizations, have coined the term 'design for policy' (e.g., Bason 2014) to signal this movement and contrast this approach to policy making from a design perspective, rather than doing 'old' policy design (Peters 2018) which approaches design from the viewpoint of policymaking.

\section{Techniques Available for Instruction}

These various trends add up to a new focus on policy design by scholars, and by governments and others trying to find new ways to address societal challenges. As a consequence, the teaching of policy design and considerations of curriculum and course design along with it, has gained new life.

As we have seen this teaching mainly occurs at the graduate level, and in more vocationally oriented courses, although some subjects being offered for undergraduates. Critical and theoretical subjects, where students are invited to engage with Simon's design science and the social turn of design research towards policy, tend to appear in undergraduate listings, but are not totally confined to this level.

Regardless of course content and approach, however, most courses use a relatively small number of key paedagogies. These extend from regular undergraduate lecture courses and graduate seminars to efforts innovate through the use of labs, cases and specific kinds of policy-relevant datasets.

\section{Teaching with Labs, Studios and Datasets}

With a renewed interest in policy design research and practice, and teaching policy design as a consequence, a new set of approaches and methods have been incorporated into the teaching of this as a subject. These tend to reflect (but are not limited to) the currently in vogue' policy design topics of design for policy, policy labs, and datasets that provide evidence for policy design.

The 'design turn' in public policy, especially, has been used as a means for focusing on the use of creativity in making public policy, in contrast to the more frequent emphasis on rational and other models of approaching policy design in traditional teaching. Teaching creative "outside the box" policymaking has been taken up by running classes as co-design sessions, where students take on assigned roles in a simulated (abbreviated) design exercise aimed at 
coming up with solutions to a specific challenge, exposes students to this process. In such classes student are typically given a scenario (for example, street violence in a particular geographic location), the need to adopt a role for themselves (such as a mayor, a young unemployed person, a local resident, and so on), and then must try and understand and empathise with others' points of view and understand what the policy problem is from multiple perspectives. This provides students with insights into how difficult it can be to simply arrive at a common understanding of the problem, and how important it is to have people affected involved in policy formulation and design.

Similarly, using class groups to 'lab' complex issues by working out how to find and then analyse relevant data (of many types), and how to present policy options in policy briefs, written with the specific contextual politics in mind is also quite common. This approach teaches students to critically evaluate different sources of evidence in the development of their arguments, and to work productively and collaboratively in groups with other students, over a short period of time, to produce a policy brief. More specifically, actual experiments (that is, online surveys) can be developed by groups to try and 'nudge' participants towards a desired behaviour. With enough time and resources (and staff with expertise on running experiments), these can be run using pools of survey respondents, and the data analysed with a view to making policy design recommendations.

Working on such datasets to produce evidence for policy design, can also be taught using small groups in classes. This method again has students working together over a short period of time, to produce a policy-relevant information to inform briefs and reports. In this case, the data provided must be analysed with a view to discovering some interesting trend or contrast. Students learn how to find and analyse relevant data, and how to use that analysis to design policy. It relies on having students who are already comfortable using statistical analysis packages or teaching basic statistical analysis as part of the subject. This exercise teaches students to ask relevant questions of the data available, understand the results of the analysis and explain how this analysis suggests certain policy design recommendations and discourages others.

Additionally, students can find innovation in the structure of the classroom itself while discovering the usefulness and relationship between policy and design. A studio setting is one that design schools employ to discuss in a group setting what works, what does not work, and what can be improved on a particular design. This format is non-traditional in policy programs or schools but breeds success within programs such as industrial design and architecture by pursuing outcomes that tend to require an iterative process, prototyping, imagining, and group evaluation. This requires a communal effort where the best ideas are not achieved in a vacuum, but instead developed through a group effort often times involving the end-user itself within the design process.

\section{What Methods to Teach?}

\subsection{Teaching with Cases vs Lectures and Seminars}

As it currently stands, the discipline is divided between the merits of case study vs textbook learning. Cases can be created for teaching the Who, What, Where, When and Why of policy 
design and can be helpful in either introducing or supplementing or reinforcing traditional textbook learning, lectures and discussion groups. Bundling various resources to create a quasi-case is useful for effective student engagement with everyday policy design issues and cases are often available from other courses and depositories that can be used or adapted for this purpose. For example, bundling multiple media sources such as newspaper articles, clips from news outlets, YouTube videos and/or documentaries for contextual information prove highly useful for linking theory and practice. After the introduction of new concepts and/or theoretical perspectives, an instructor may offer this compiled material that relates to the description of Who, What, Where, When and Why of the policy design. The aim is to ensure student engagement with the real-life situation through theoretically informed analysis and/or exploration.

Case teaching approaches often offers a useful avenue to illustrate how theoretical and conceptual approaches can be operationalised in the classroom in a real-world context. Case studies may be organised in five different forms which have their unique purpose for student engagement (Ronstadt 1994; Harling and Akridge 1998; Walker 2009: 216-17). Anecdotes are useful for the introduction of a new concept through identify the problem and illustrate policy actions taken to address that problem. Technical problem-solving cases enable students to use a specific theoretical or conceptual tool to solve a problem. Short-structured cases challenge students to apply their knowledge and offer solutions to multiple problems raised by the instructor. Long- structured cases relate to complex problems where there are no clear solutions which require students to collect and analyse detailed data for the interpretation of the situation and arrive at relevant solutions. Ground-breaking case's structure real-life situations with a problem-solving perspective where students focus on analysis rather than problem solving.

Utilization of case studies helps student engagement to make sense of theory as an analytical tool to understand the theoretical approaches in policy design and implementation practise and improve their skills to select and analyse policy-relevant information.

\subsection{Looking at Processes or Searching for Causality?}

Another division in current design courses relates to their emphasis on either process tracing or causal mechanisms. These are two separate methods in policy design teaching which should not be conflated. The former focuses on describing and understanding the unfolding of a sequence of events over time (Bennett and Checkel, 2015:9), whilst the emphasis in latter is on the causal chains connecting specific kinds of structural and institutional level policy phenomena with individual policy behaviour and collective outcomes (Hay, 2016; Mayntz, 2004, Bakir 2020).

\subsection{Engaging with the Community}

Perhaps one of the more important aspects of associating policy with design is its ability to develop abstract solutions to real-world problems. Each program that employs the usage of design within the context of policy decision-making and its varied outcomes will have access to the surrounding community which can serve as a mutually beneficial testing ground for students and instructors. 
Non-profits, local government, the citizenry, and even the local business community can all serve as recipients of the designerly experimentation taking place within the classroom. By engaging in this sort of educational exchange - either formally through internships and placements or informally through talks and visits - students are able to apply the concepts they have learned within the community. This process allows the student and the community the time and venue needed to partake in cost-effective low stakes exchange which leaves room for highly creative and non-traditional thinking to take place. By addressing 'wicked problems' (Rittel 1972), or problems which often times do not have enough definition to be solved through traditional means, students are able to find innovative ways of addressing old problems facing society and, often, to see why they might, or might not, work in practice.

Design research methodology, or methods of design, can be a framework of individual methods used to elicit information or discover vital aspects of a product or system (Martin, Hanington 2012). Within the interface of policy and design students can use various methods of design to develop conclusions that can be used through field research to reach conclusions about the subject at large. A student may conduct non-traditional interviews or surveys as well as behavioural maps, user personas, or role-playing in order to arrive at conclusions that traditional means of inquiry may not provide the best solution for. The flexibility of the design process in conjunction with policy makes for a much more open and creative environment to tackle old problems in new ways.

\section{Conclusion: Looking to the Future}

The future interplay between policy and design appears to be very bright and necessary for addressing unforeseen circumstances brought on by rapid societal advancement in numerous public-facing sectors. Given this, it is of the utmost importance to bring together the work of researchers, designers, and academics in order to critically explore and define the relationship between policy and design and assess how best to promote it within an academic context.

Presently, the topic is very much open for debate as to how these two concepts differ, relate, and interact with one another in complex ways. As discussed above while there are general agreements on the scope of policy design and policy-relevant design instruction, there exist several different ways in which policy design can be taught, with differences in course content and methodologies originating in the policy studies tradition and the "design for policy" approach. The former sees the need for policy to instrumentally embody a conscious design of its own making while the later holds that design is a pre-existing field of study unto itself that can be employed in accordance with policy formation (Bason, 2014; Howlett, 2019).

However, beyond that important distinction courses in either orientation can choose from a variety of paedagogies and methods to convey wisdom and knowledge to students. Although explicitly connected to the same subject matter, each different approach and direction is built upon differing criteria and parameters thus creating multiple unique starting points for instructors, meaning some courses in these two orientations may at times overlap while at other times deviating considerably. 
Given this diversity and the lack of a 'one size fits all' paedagogy, it is not surprising that there has been growth in the number of books and articles as well as conference topics on the subject of policy design instruction, indicating a strong need for increased attention to policy design paedagogy for years to come (Mortati, 2019). More academic rigor in the future may determine which of these different approaches works best in which circumstances and with which set of students. At present, however, embracing a diversity of approaches and 'letting a thousand flowers bloom' are the watchwords of instruction in the field.

\section{References}

Annual Review of Policy Design Vol 52017

https://ojs.unbc.ca/index.php/design/issue/view/105/showToc

Annual Review of Policy Design Vol 72019

https://ojs.unbc.ca/index.php/design/issue/view/111/showToc

Bakir, C. (2020). "Actions, Contexts, Mechanisms and Outcomes in Macroprudential Policy Design and Implementation", Public Policy and Administration

Bason, C. (2016). Preface. In C. Bason, Ed Design for Policy London, UK: Taylor and Francis.

Bason, Christian, and Andrea Schneider. "Public Design in Global Perspective; Empirical Trends." In Design for Policy, edited by Christian Bason, New edition., 23-40. Farnham, Surrey; Burlington, VT: Gower Pub Co, 2014.

Bobrow, D. B., and J. S. Dryzek. Policy Analysis by Design. Pittsburgh: University of Pittsburgh Press, 1987.

Bobrow, Davis. "Policy Design: Ubiquitous, Necessary and Difficult." In Handbook of Public Policy, edited by B. Guy Peters and Jon Pierre, 75-96. SAGE, 2006.

Bridgman and Davis (2004) The Australian Policy Handbook. Sydney: Allen \& Unwin.

Clarke, Amanda, and Jonathan Craft. "The Vestiges and Vanguards of Policy Design in a Digital Context." Canadian Public Administration 60, no. 4 (December 1, 2017): 476-97.

Colebatch, Hal K. "What Work Makes Policy?” Policy Sciences 39, no. 4 (November 2006): 30921.

Craft, Jonathan, and John Halligan. "Assessing 30 Years of Westminster Policy Advisory System Experience." Policy Sciences, July 13, 2016, 1-16.

Cross, N. (1982). Designerly ways of knowing. Design Studies, 3(4), 221-227. doi:10.1016/0142-694x(82)90040-0

deLeon, P. "Policy Formulation: Where Ignorant Armies Clash by Night." Policy Studies Review 11, no. 3/4 (1992): 389-405.

Dorst, K (2015) Frame innovation: Create new thinking by design. Cambridge MA: MIT Press.

Dorst, Kees, and Judith Dijkhuis. "Comparing Paradigms for Describing Design Activity." Design Studies 16, no. 2 (April 1995): 261-74.

Dorst, Kees. "The Core of 'Design Thinking' and Its Application." Design Studies 32, no. 6 (November 2011): 521-32.

Dryzek, J. S., and B. Ripley. "The Ambitions of Policy Design." Policy Studies Review 7, no. 4 (1988): 705-19.

El-Talaiwi, Ola, Nihit Goyal and Michael Howlett, "Big Data Instruction in Public Policy Schools Worldwide" in L. Pal ed The Future of Policy Schools, Cheltenham, Edward Elgar 2021 forthcoming 
Feindt, Peter H, and Andrew Flynn. "Policy Stretching and Institutional Layering: British Food Policy between Security, Safety, Quality, Health and Climate Change." British Politics 4, no. 3 (2009): 386-414.

Fraussen, Bert, and Darren Halpin. "Think Tanks and Strategic Policy-Making: The Contribution of Think Tanks to Policy Advisory Systems." Policy Sciences, February 16, 2016, 1-20.

Haelg, Leonore, Sebastian Sewerin, and Tobias S. Schmidt. "The Role of Actors in the Policy Design Process: Introducing Design Coalitions to Explain Policy Output." Policy Sciences 53, no. 2 (June 1, 2020): 309-47.

Harling, K. F., \& Akridge, J. (1998). Using the case method of teaching. Agribusiness, 14(1), 114.

Hay C (2016) Process tracing: A laudable aim or a high-tariff methodology? New Political Economy 21(5): 500-504

He, Alex Jingwei, Allen Lai, and Xun Wu. "Teaching Policy Analysis in China and the United States: Implications for Curriculum Design of Public Policy Programs." Policy and Society, Teaching Public Policy: Global Convergence or Difference?, 35, no. 4 (December 1, 2016): 385-96.

Heijden, Jeroen van der. "Institutional Layering: A Review of the Use of the Concept." Politics 31, no. 1 (January 10, 2011): 9-18.

Hood, C. The Tools of Government. Chatham: Chatham House Publishers, 1986.

Howlett, M., and M. Ramesh. Studying Public Policy: Policy Cycles and Policy Subsystems. Toronto: Oxford University Press, 2003.

Howlett, M. (2019). Basic Concepts and Vocabulary. In The Policy Design Primer: Choosing the Right Tools for the Job (p. 3). New York, NY: Routledge.

Howlett, Michael P., and Jeremy Rayner. "Patching vs Packaging: Complementary Effects, Goodness of Fit, Degrees of Freedom and Intentionality in Policy Portfolio Design." SSRN Scholarly Paper. Rochester, NY: Social Science Research Network, 2013.

Howlett, Michael, and I. Mukherjee. "Design and Non-Design in Policy Formulation: Where Knowledge Meets Power in the Policy Process." In Handbook of Policy Formulation. Cheltenham: Edward Elgar, 2017.

Howlett, Michael, and Ishani Mukherjee, eds. Handbook of Policy Formulation. Cheltenham: Edward Elgar, 2017.

Howlett, Michael, and Ishani Mukherjee. "The Contribution of Comparative Policy Analysis to Policy Design: Articulating Principles of Effectiveness and Clarifying Design Spaces." Journal of Comparative Policy Analysis: Research and Practice 20, no. 1 (January 1, 2018): 72-87.

Howlett, Michael, Ishani Mukherjee, and Jeremy Rayner. "Understanding Policy Designs Over Time: Layering, Stretching, Patching and Packaging." In Routledge Handbook of Policy Design, edited by Michael Howlett and Ishani Mukherjee, 136-44. New York: Routledge, 2018.

Howlett, Michael. "Dealing with the Dark Side of Policy-Making: Corruption, Malfeasance and the Volatility of Policy Mixes." In Handbook on Corruption, Ethics and Integrity in Public Administration, edited by Adam Graycar, 67-79. Cheltenham: Edward Elgar, 2020.

Howlett, Michael. "The Temporal Dimension(s) of Policy Designs: Resilience, Robustness and the Sequencing of Tools in Policy Mixes." International Review of Public Policy 1, no. 1 (2019): 27-45.

Howlett, Michael. Designing Public Policies: Principles and Instruments. 2nd Edition. London: Routledge, 2011. 
Howlett, Michael. Designing Public Policies: Principles and Instruments. 2nd Edition. London: Routledge, 2019a.

Howlett, Michael. The Policy Design Primer: Choosing the Right Tool for the Job. New York: Routledge, 2019b.

Hustedt, Thurid. "Analyzing Policy Advice: The Case of Climate Policy in Germany." Central European Journal of Public Policy 7, no. 1 (June 30, 2013): 88-110.

Johansson-Sköldberg, Ulla, Jill Woodilla, and Mehves Çetinkaya. "Design Thinking: Past, Present and Possible Futures." Creativity and Innovation Management 22, no. 2 (2013): 121-46.

Johnson, Jeffrey, and Matthew Cook. "Policy Design: A New Area of Design Research and Practice." In Complex Systems Design \& Management, edited by Aiguier M., Boulanger F., Krob D., and Marchal C., 51-62. Springer, Cham, 2014.

Lee, Celia, and Liang Ma. "The Role of Policy Labs in Policy Experiment and Knowledge Transfer: A Comparison across the UK, Denmark, and Singapore." Journal of Comparative Policy Analysis: Research and Practice (October 13, 2019): 1-17.

Leitner, Christine, and Christian M. Stiefmueller. "Disruptive Technologies and the Public Sector: The Changing Dynamics of Governance." In Public Service Excellence in the 21st Century, edited by Alikhan Baimenov and Panos Liverakos, 237-74. Singapore: Springer Singapore, 2019.

Lewis, Jenny M, Michael McGann, and Emma Blomkamp. "When Design Meets Power: Design Thinking, Public Sector Innovation and the Politics of Policymaking." Policy \& Politics 48, no. 1 (January 1, 2020): 111-30.

Linder, S. H., and B. G. Peters. "A Metatheoretic Analysis of Policy Design." In Advances in Policy Studies Since 1950, edited by W. N. Dunn and R. M. Kelly, 201-38. New Brunswick: Transaction Publishers, 1992.

Linder, S. H., and B. G. Peters. "From Social Theory to Policy Design." Journal of Public Policy 4, no. 3 (1984): 237-59.

Linder, S. H., and B. G. Peters. "Policy Formulation and the Challenge of Conscious Design." Evaluation and Program Planning 13 (1990b): 303-11.

Linder, S. H., and B. G. Peters.. "Research Perspectives on the Design of Public Policy: Implementation, Formulation, and Design." In Implementation and the Policy Process: Opening up the Black Box, edited by D. J. Palumbo and D. J. Calista, 51-66. New York: Greenwood Press, 1990c.

Linder, S. H., and B. G. Peters.. "The Analysis of Design or the Design of Analysis?" Policy Studies Review 7, no. 4 (1988): 738-50.

Linder, S. H., and B. G. Peters. "The Logic of Public Policy Design: Linking Policy Actors and Plausible Instruments." Knowledge in Society 4 (1991): 125-51.

Linder, S., and B. G. Peters. "The Design of Instruments for Public Policy." In Policy Theory and Policy Evaluation: Concepts, Knowledge, Causes, and Norms, edited by S. S. Nagel, 10319. New York: Greenwood Press, 1990a.

Linder, Stephen H, and B. Guy Peters. "A Design Perspective on Policy Implementation: The Fallacies of Misplaced Prescription." Review of Policy Research 6, no. 3 (February 1, 1987): 459-75.

Lindquist, E. "Organizing for Policy Implementation: The Emergence and Role of Implementation Units in Policy Design and Oversight." Journal of Comparative Policy Analysis: Research and Practice 8, no. 4 (2006): 311-24.

Manski, Charles F. "Policy Analysis with Incredible Certitude." The Economic Journal 121, no. 554 (August 1, 2011): F261-89. 
Manski, Charles F. Public Policy in an Uncertain World: Analysis and Decisions. Cambridge, Mass: Harvard University Press, 2013.

Manwaring, Rob, Josh Holloway, and Brian Coffey. "Engaging Industry in Curriculum Design and Delivery in Public Policy Teaching: A Strategic Framework." Teaching Public Administration, June 27, 2019,

Martin, B., \& Hanington, B. M. (2012). Universal methods of design: 100 ways to research complex problems, develop innovative ideas, and design effective solutions. Beverly, MA: Rockport.

May, Peter J. "Policy Design and Implementation." In Handbook of Public Administration, edited by Peters, B. Guy and Jon Pierre, 223-33. Beverly Hills: Sage, 2003.

May, Peter J. "Policy Design and Implementation." In Handbook of Public Administration, edited by Peters, B. Guy and Jon Pierre, 223-33. Beverly Hills: Sage, 2003.

Mayntz R (2004) Mechanisms in the analysis of social macro-phenomena. Philosophy of the Social Sciences 34(2): 237-259.

Mayntz R (2016) Process tracing, abstraction, and varieties of cognitive interest. New Political Economy 21(5): 484-488.

McNutt, Kathleen, and Leslie A Pal. "'Modernizing Government': Mapping Global Public Policy Networks." Governance 24, no. 3 (July 1, 2011): 439-67.

Morgan, M. G., and M. Henrion. Uncertainty: A Guide to Dealing with Uncertainty in Quantitative Risk and Policy Analysis. Cambridge: Cambridge University Press, 1990.

Mortati, M. (2019). The Nexus between Design and Policy: Strong, Weak, and Non-Design Spaces in Policy Formulation. The Design Journal, 22(6), 775.

Mukherjee, Ishani, and Sarah Giest. "Behavioural Insights Teams (BITs) and Policy Change: An Exploration of Impact, Location, and Temporality of Policy Advice." Administration \& Society, May 4, 2020, 0095399720918315.

Nelson, David, and Susan Webb Yackee. "Lobbying Coalitions and Government Policy Change: An Analysis of Federal Agency Rulemaking." The Journal of Politics 74, no. 02 (2012): 33953.

Newman, Joshua, and Martha Widdi Nurfaiza. "Policy Design, Non-Design, and Anti-Design: The Regulation of e-Cigarettes in Indonesia." Policy Studies (January 3, 2020): 1-18.

Olejniczak, Karol, Sylwia Borkowska-Waszak, Anna Domaradzka-Widła, and Yaerin Park. "Policy Labs: The next Frontier of Policy Design and Evaluation?" Policy \& Politics 48, no. 1 (January 1, 2020): 89-110.

Pal, Leslie A., and lan D. Clark. "Teaching Public Policy: Global Convergence or Difference?" Policy and Society, Teaching Public Policy: Global Convergence or Difference?, 35, no. 4 (December 1, 2016a): 283-97.

Pal, Leslie A., and Ian D. Clark. "The MPA/MPP in the Anglo-Democracies: Australia, Canada, New Zealand, the United Kingdom, and the United States." Policy and Society, Teaching Public Policy: Global Convergence or Difference?, 35, no. 4 (December 1, 2016): 299-313.

Peters, B. Guy, Pauline Ravinet, Michael Howlett, Giliberto Capano, Ishani Mukherjee, and Meng Hsuan Chou. Designing for Policy Effectiveness: Defining and Understanding a Concept. Elements Series. Cambridge: Cambridge University Press, 2018.

Peters, BG (2018) Policy problems and policy design. Cheltenham: Edward Elgar.

Rasmussen, Ken, and Derrick Callan. "Schools of Public Policy and Executive Education: An Opportunity Missed?" Policy and Society, Teaching Public Policy: Global Convergence or Difference?, 35, no. 4 (December 1, 2016): 397-411. 
Rein, M., and D. Schon. "Frame-Critical Policy Analysis and Frame-Reflective Policy Practice." Knowledge and Policy 9, no. 1 (1996): 85-105.

Rittel, H.W.J., Webber, M.M. Dilemmas in a general theory of planning. Policy Sci 4, 155-169 (1973).

Ronstadt, R. (1994). The art of case analysis (3rd ed.). Dana Point, CA: Lord Publishing.

Salamon, L. M. The Tools of Government: A Guide to the New Governance. New York: Oxford University Press, 2002.

Schneider, A. L., and H. Ingram. "Behavioural Assumptions of Policy Tools." Journal of Politics 52, no. 2 (1990a): 511-29.

Schneider, A., and H. Ingram. "Social Construction of Target Populations: Implications for Politics and Policy." American Political Science Review 87, no. 2 (1993): 334-47.

Schneider, A., and H. Ingram. Policy Design for Democracy. Lawrence: University Press of Kansas, 1997.

Schneider, A., and H. Ingram.. "Policy Design: Elements, Premises and Strategies." In Policy Theory and Policy Evaluation: Concepts, Knowledge, Causes and Norms, edited by S. S. Nagel, 77-102. New York: Greenwood, 1990b.

Schneider, A., and H. Ingram.. "Social Constructions and Policy Design: Implications for Public Administration." Research in Public Administration 3 (1994): 137-73.

Schneider, Anne L, and Helen M Ingram, eds. Deserving and Entitled: Social Constructions and Public Policy. SUNY Series in Public Policy. Albany: State University of New York, 2005.

Schon, D. A., and M. Rein. Frame Reflection: Towards the Resolution of Intractable Policy Controversies. New York: Basic Books, 1994.

Schon, Donald A. "Designing: Rules, Types and Words." Design Studies 9, no. 3 (July 1988): 181-90.

Schon, Donald A. Educating the Reflective Practitioner: Toward a New Design for Teaching and Learning in the Professions. Jossey-Bass, 1990.

Schon, Donald A. The Reflective Practitioner: How Professionals Think In Action. Basic Books, 1984.

Simon, H (1969) Simon, Herbert A. The Sciences of the Artificial. Cambridge, Mass.: MIT Press

Simons, Arno, and Jan-Peter Voss. "The Concept of Instrument Constituencies: Accounting for Dynamics and Practices of Knowing Governance." Policy and Society (2017).

Thelen, Kathleen. How Institutions Evolve: The Political Economy of Skills in Germany, Britain, the United States and Japan. Cambridge: Cambridge University Press, 2004.

Undergraduate Students, International Journal of Teaching and Learning in Higher Education, 20(2), 214-225

Verbruggen, Aviel. "Preparing the Design of Robust Climate Policy Architectures." International Environmental Agreements: Politics, Law and Economics 11, no. 4 (November 1, 2011): 275-95.

Veselý, Arnošt. "Policy Advice as Policy Work: A Conceptual Framework for Multi-Level Analysis." Policy Sciences, June 8, 2016, 1-16.

Veselý, Arnošt. "Policy Formulation Redesigned: A New Understanding of Policy Design and Its Implications for Instruction."

Waks, Leonard J. "Donald Schon's Philosophy of Design and Design Education." International Journal of Technology and Design Education 11, no. 1 (January 1, 2001): 37-51.

Walker, C. (2009). Teaching Policy Theory and its Application To Practice Using Long Structured Case Studies: An Approach that Deeply Engages

Walker, W. E., and V. A. W. J. Marchau. "Dealing with Uncertainty in Policy Analysis and Policymaking." Integrated Assessment 4, no. 1 (2004): 1-4. 
Walker, Warren E., Robert J. Lempert, and Jan H. Kwakkel. "Deep Uncertainty." In Encyclopedia of Operations Research and Management Science, edited by Saul I. Gass and Michael C. $\mathrm{Fu}, 395-402$. Springer, Boston, MA, 2013a.

Walker, Warren E., Vincent A.W. J. Marchau, and Jan H. Kwakkel. "Uncertainty in the Framework of Policy Analysis." In Public Policy Analysis: New Developments, edited by Wil A. H. Thissen and Warren E. Walker, 2013th ed., 215-60. New York: Springer, 2013b

Weimer, D. L. "The Craft of Policy Design: Can It Be More Than Art?" Policy Studies Review 11, no. 3/4 (1992): 370-88.

Wellstead, Adam. "The Rise of Policy Innovation Labs: A Catalog of Policy Innovation in the United States." SSRN Scholarly Paper. Rochester, NY: Social Science Research Network, January 3, 2020.

Wu, Xun, Allen Yu-Hung Lai, and Do Lim Choi. "Teaching Public Policy in East Asia: Aspirations, Potentials and Challenges." Journal of Comparative Policy Analysis: Research and Practice 14, no. 5 (2012): 376-90.

Young, E. and L. Quinn (2002) Writing Effective Public Policy Papers: A Guide To Policy Advisers in Central and Eastern Europe. Budapest: LGI.

Author Bios:

Azad Singh Bali is Senior Lecturer in Public Policy and holds a joint appointment at the at the Crawford School of Public Policy and The School of Politics and International Relations.

Caner Bakır is a professor of political science with particular emphasis on international and comparative political economy, and public policy and administration of the College of Administrative Sciences and Economics at Koç University.

Michael Howlett is Burnaby Mountain Professor and Canada Research Chair in the Department of Political Science at Simon Fraser University.

Jenny M. Lewis is Professor of Public Policy and is the President of the International Research Society for Public Management. She is a Fellow of the Academy of Social Sciences Australia, and an expert on policy making, policy design and public sector innovation.

Scott Schmidt is adjunct professor at Georgetown University. 